\title{
Development of disposable carbon nanofibers electrodes supported on filters
}

\author{
Ana Erica Paramo ${ }^{a}$, Susana Palmero $^{a} *$, Aranzazu Heras $^{a}$, Alvaro Colina $^{a}$ and David Ibañez $^{a}$ \\ a Department of Chemistry, Universidad de Burgos, Plaza Misael Bañuelos s/n, E- 09001 Burgos, Spain. \\ * e-mail: spaldi@ubu.es
}

Received: ((will be filled in by the editorial staff))

Accepted: ((will be filled in by the editorial staff))

\begin{abstract}
The purpose of this work is to develop simple and reproducible ways to fabricate carbon nanofibers (CNFs) electrodes. Disposable CNFs electrodes were fabricated after filtering CNFs through polytetrafluoroethylene filters (PTFE), using directly as electrodes these filters with the CNFs film. The electrochemical behaviour of CNFs/PTFE electrodes were tested with ferrocenemethanol and tris(2,2'-bypyridyl)dichlororuthenium(II) (Ru(bipy) ${ }_{3}{ }^{2+}$ ). As a proof of concept of the analytical usefulness of the CNFs/PFTE electrodes, the study of vitamin $\mathrm{B}_{12}$ was carried out. Multivariate calibrate has been successfully used to determine vitamin $B_{12}$ in a complex medium with vitamins $B_{1}$ and $B_{6}$ as interferents.
\end{abstract}

Keywords: Carbon nanofibers, disposable electrodes, vitamin $\mathrm{B}_{12}$, electrochemistry.

DOI: 10.1002/elan.((will be filled in by the editorial staff))

\section{Introduction}

Carbon nanofibers (CNFs) are $\mathrm{sp}^{2}$-based linear and cylindrical nanostructures with no hollow core with lengths in the order of $\mu \mathrm{m}$, and diameters between some tens up to some hundreds of $\mathrm{nm}[1,2]$. They combine flexibility with high specific area and high mechanical strength. CNFs geometry is truncated conical or planar layer of carbon periodically stacked along the filament length [3] They have many chemically active edge sites on the outer wall that confer them high capacitance values because, in general, the edge sites show higher capacitance values than basal planes [4], and make them suitable materials as catalysts support $[5,6]$, storage systems like fuel cells [7-9], polymer reinforcements [10], and enhancement of the mechanical properties of cementitious materials [11]. Their intrinsic electrical conductivity makes CNFs as suitable material to modified electrode surfaces, changing the pristine properties of the support materials and increasing significantly their potential applications. To fabricate electrodes modified with CNFs or other carbon nanomaterial, firstly a homogeneous solution of the carbon material is prepared. Next, a small portion of this solution is fixed on a conductive surface such as platinum, gold or carbon by drop casting or spin coating [12-16], or is mixed with other agglutinative materials to obtain the well-known carbon paste electrodes [12,17-20].

In this work, a new methodology to prepare pure CNFs electrodes, without any other conducting support, is proposed. Based on works related to the generation of carbon nanotubes free-standing sheets, the so-called buckypapers or carbonpapers [21-23], we proposed the use of filters with homogeneous conductive CNFs films as working electrodes in electrochemical experiments. This simple and easy 
experimental approach allows us to perform high quality electrochemical determinations. A new electrochemical cell has been also developed to use the CNFs electrodes in the electrochemical experiments.

Very interesting applications, in the field of sensors and biosensors, have been also proposed using CNFs electrodes $[1,17,24-26]$, usually fixing the CNFs on a conductive surfaces [27,28]. Specially, CNFs have been successfully used in electroanalysis to study some interesting biomolecules such as glucose [28], dopamine [17,29], catechol [18,30], purine bases [14], xanthine [31], hydrogen peroxide [32], or NADH $[15,16]$.

In this work, as a proof of concept, and to demonstrate the analytical usefulness of the CNFs electrodes, the determination of vitamin $B_{12}$ has been addressed. Vitamin $B_{12}$ or cyanocobalamin is a very important biomolecule with carbon-metal bonds and its deficiency may lead to different medical problems such as abnormal cell growth or nerve degeneration [33]. Its structure consists of a cobalt atom coordinatively bounded to the four nitrogens of the coring ring, a nucleotide chain terminated by the 5.6dimethylbenzimidazole group, and the $\mathrm{CN}$ group [34,35]. Electrochemical studies of oxidation of vitamin $B_{12}$ are relevant to elucidate the mechanism of reaction in biological media in which cobalamin species take part. Many methods such as UV-Vis spectroscopy, fluorimetry, capillary electrophoresis, electroanalysis, mass spectrometry, atomic absorption spectrometry or high-performance liquid chromatography are usually used to determine vitamin $B_{12}$ [33]. Between them, electrochemical methods have emerged as clean and direct analytical methods that avoid some drawbacks of other methods usually linked to sample preparation. Recently, many methods to modify electrode surfaces have been proposed. In this work, the use of CNFs electrodes fixed on an inert surface, such as the filter used to filter them, without any other component or material is proposed. The results presented below demonstrate the good performance of these electrodes and their usefulness in the electroanalysis of vitamin $\mathrm{B}_{12}$. It is noteworthy that the analysis of vitamin $\mathrm{B}_{12}$ has been carried out in a complex medium using multivariate calibration to assess its concentration.

\section{Experimental}

\subsection{Chemical}

Ferrocenemethanol $(\mathrm{FcMeOH}), \quad(97 \%$ Acros Organics), tris(2,2'-bypyridyl)dichlororuthenium(II) hexahydrate, $\left(\mathrm{Ru}\left(\right.\right.$ bipy) $\left.{ }_{3}{ }^{2+}\right),(98 \%$ Acros Organics), potassium nitrate, $\mathrm{KNO}_{3}$, (Merck) and potassium chloride, $\mathrm{KCl}$, (Acros Organics) were used as received, being all of them of analytical grade. $\mathrm{FcMeOH}$ aqueous solutions were prepared using $0.1 \mathrm{M} \mathrm{KCl}$ as supporting electrolyte. $\mathrm{Ru}$ (bipy) $)_{3}{ }^{2+}$ aqueous solutions were prepared using $0.2 \mathrm{M} \mathrm{KNO}_{3}$ as supporting electrolyte. Vitamin $\mathrm{B}_{12}(>98 \%$ Sigma Aldrich) was dissolved in a PBS buffer solution of $0.1 \mathrm{M}$ $\mathrm{H}_{2} \mathrm{PO}_{4} / \mathrm{HPO}_{4}{ }^{2-}$ (Merck) by adjusting the $\mathrm{pH}$ with $\mathrm{H}_{3} \mathrm{PO}_{4}$ (Panreac) to $\mathrm{pH}=5$.

Ethanol (Merck), polytetrafluoroethylene filters (PTFE) (pore size $0.1 \mu \mathrm{m}$; JVWP01300, Millipore Omnipore), $175 \mu \mathrm{m}$ thick sheets of polyethylene terephthalate (PET, HiFi Industrial Film), silver conductive paint (Electrolube) for the electrical contacts, and epoxy protective overcoat (242-SB de ESL Europe) as insulator, were used for the preparation of CNFs electrodes.

CNFs nanofibers were vapour grown graphitized carbon fibers (VGCF®) from Showa Denko.

All experiments were performed at room temperature.

\subsection{Instrumentation}

Electrochemical experiments were carried out with an AUTOLAB PGSTAT 10 or an CHI9000 potentiostat/galvanostat electrochemical system using the three-electrode home-made electrochemical cell, and a CNFs/PTFE electrode as working electrode, a platinum wire as counter electrode, and a home-made $\mathrm{Ag} / \mathrm{AgCl} / 3 \mathrm{M} \mathrm{KCl}$ as reference electrode.

All solutions were daily prepared by using highquality water (resistivity of $18.2 \mathrm{M} \Omega \cdot \mathrm{cm}$, Milli-Q A10 system, Millipore).

A tip-sonicator (CY-500, Optic ivymen System) was also used to properly disperse the CNFs in ethanol.

SEM images were obtained with a Zeiss Ultra Plus field-emission scanning electron microscope.

Raman spectra were registered using a Confocal Raman Voyage (BWTEK) with a 20x objective. The laser power used was $5 \mathrm{~mW}$ and the laser wavelength was $532 \mathrm{~nm}$.

\subsection{Fabrication of CNFs/PTFE electrodes}

New and reproducible electrodes were developed in this work based on previous works performed in our 
laboratory [36], but in this case, the filter was not removed after filtration. This method consists of six consecutive steps. Firstly, a CNFs dispersion 0.1 $\mathrm{mg} / \mathrm{mL}$ in ethanol was prepared. To get an appropriate homogenization, the dispersion was sonicated for 20 minutes using the tip-sonicator. Then, a volume of 400 $\mu \mathrm{L}$ was filtered under vacuum through a hydrophilic PTFE filter obtaining an homogeneous film of CNFs that was dried for 5 minutes at room temperature and for 2 hours at $60^{\circ} \mathrm{C}$ in an oven. To get a planar carbon nanofibers/PTFE filter electrode a hydraulic press was used, applying 15 tons for $60 \mathrm{~s}$. Afterwards, the $\mathrm{CNF} / \mathrm{PTFE}$ filter was fixed on a clean PET sheet with an inert epoxy insulating paint applied in the external section of the filter, taking special care to avoid any contact between the epoxy paint and the CNFs. The electrical contact was made using conductive silver paint, creating a small line from the CNFs film to the end of PET sheet (Figure 1A), that was dried in an oven at $60^{\circ} \mathrm{C}$ for 30 minutes. Then, part of this silver electrical contact was electrically isolated using an epoxy protective overcoat (Figure 1B), that was dried in an oven at $60^{\circ} \mathrm{C}$ for $120 \mathrm{~min}$. A Teflon mask was used to cover the CNFs film and reproduce the electrode area (Figure 1C). The final dimensions of the $\mathrm{CNF} / \mathrm{PTFE}$ electrode are $35 \mathrm{~mm}$ long and $10 \mathrm{~mm}$ wide.

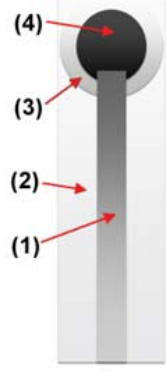

A

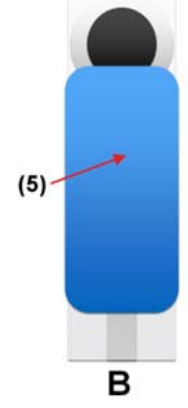

(6)

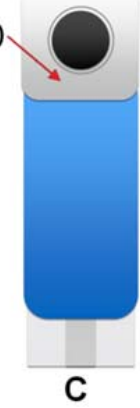

Fig. 1: Schematic plot of the key steps related to the fabrication of CNFs/PTFE electrodes. (A) PTFE filter (3) with the CNFs film (4) fixed on the PET sheet (2) with the electrical silver contact (1). (B) Epoxy protective overcoat (5) to isolate the silver contact. (C) PTFE mask (6) covering part of carbon nanofibers.

\subsection{Development of the electrochemical cell.}

The new CNF/PTFE electrodes are flexible. Thus, an electrochemical cell (Figure 2) was designed and fabricated to properly place the flexible CNF/PTFE electrodes and to reproduce the position of the three electrode system. This cell consists of two PTFE parts.
The bottom part was a rectangular prism $(10 \times 15 \times 60$ $\mathrm{mm}$ ) with a rabbet to place the CNF/PTFE working electrode. The upper part of the cell was a rectangular prism $(20 \times 15 \times 60 \mathrm{~mm})$ with a bridge $(13 \times 15 \times 28$ $\mathrm{mm}$ ) that helped to hold the CNFs/PTFE electrode and made easier the addition of the solution. Suitable holes for the reference electrode (RE) and the counter electrode (CE) were drilled on the upper part of the cell, that allowed us to reproduce the position and the distance from the RE and CE to the CNFs electrode. The upper and the bottom parts were joined with a rotatable axis to easily change the CNFs/PTFE electrode. The design of the cell also facilitates the addition and change of the solution by dispensing a small drop of solution $(150 \mu \mathrm{L})$ directly on the working electrode, guaranteeing the contact of the three electrodes with the solution in a very simple and effective way.

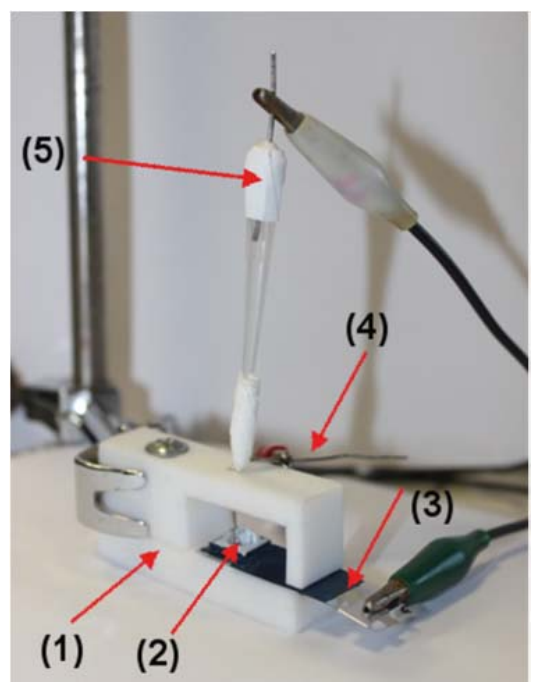

Fig. 2: Photograph of the home-made PTFE electrochemical cell. (1) Cell body, (2) drop sample, (3) CNFs working electrode, (4) counter electrode, (5) reference electrode.

\section{Results and discussion}

\subsection{Characterization of CNFs.}

Prior to transfer the CNFs to the PTFE filter and construct the electrode, CNFs were characterized to confirm that good dispersions were obtained in the solvent, and to evaluate some of their physical characteristics.

With this objective, the CNFs were characterized by SEM. Samples for microscopy analysis were prepared from a dispersion of nanofibers in ethanol according the methodology described above. An aliquot of $2 \mu \mathrm{L}$ 
was dropped on a glassy carbon surface and dried at room temperature for two hours before being characterized.

Figure 3 shows the SEM image of one of these samples, and as can be appreciated, CNFs are well dispersed to take advantage of their particular properties in electrochemical measurements. From this image is also estimated that the CNFs have a mean outer diameter of $154 \pm 14 \mathrm{~nm}$.

One of the most significant and informative techniques to characterized carbon materials is Raman spectroscopy because allow to differentiate carbon allotropes. Therefore, CNFs/PTFE electrodes were characterized by Raman spectroscopy.

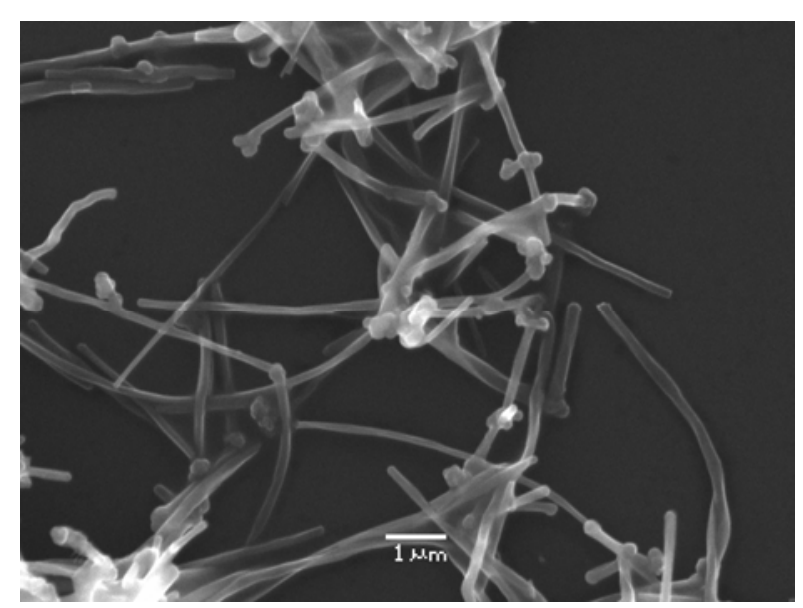

Fig. 3. SEM image of CNFs dispersed in ethanol.

The Raman spectra shows three main bands peaking at $1345 \mathrm{~cm}^{-1}, 1576 \mathrm{~cm}^{-1}$, and $2690 \mathrm{~cm}^{-1}$ (Figure 4). The most intense band at $1576 \mathrm{~cm}^{-1}$, usually called Gmode, is attributed to the $\mathrm{E}_{2 \mathrm{~g}}$ phonon related to the inplane $\mathrm{C}=\mathrm{C}$ stretching vibrations [34,35]. Meanwhile, the band at $1345 \mathrm{~cm}^{-1}$, called D-mode, is assigned to the breathing mode of $\mathrm{A}_{\mathrm{gg}}$ symmetry with information related to structural disorder both in the graphitic basal planes and in their edges [37-39]. On this way, this Dband has low intensity in well-organized carbon materials while in more disordered materials its intensity can be even more intense than the G-band. These two strong bands are consistent with graphitic carbon samples and it is established that the intensity ratio of D-band/G-band $\left(\mathrm{I}_{\mathrm{D}} / \mathrm{I}_{\mathrm{G}}\right)$ is inversely proportional to the graphitic order in the CNFs [3741]. From our data (Figure 4 ) a $I_{D} / I_{G}$ ratio of 0.17 is obtained, indicating that a relatively low-disordered crystalline carbons in the CNFs [34,38]. The third band that emerges at $2690 \mathrm{~cm}^{-1}$, the so-called G' or 2D band, corresponds to a second-order band. As it has been described by Tascon and Maldonado [36,38], this G'-band is well-defined for ordered and, therefore, crystalline graphitic carbons, being in agreement with conclusions extracted from $\mathrm{I}_{\mathrm{D}} / \mathrm{I}_{\mathrm{G}}$ ratio value. Furthermore, the weak shoulder slightly appreciated in G'-band at Raman shifts lower than $2690 \mathrm{~cm}^{-1}$, reveals the graphitization of the CNFs, because it splits in two well-defined bands for the most graphitized materials $[36,39]$. Others weak and ill-defined bands in Raman spectrum are also observed (Figure 4). The shoulder around $1490-1500 \mathrm{~cm}^{-1}$ is ascribed to amorphous $\mathrm{C}=\mathrm{C}$ forms of carbon. Its negligible value compared to that at $1576 \mathrm{~cm}^{-1}$ reveals that there is a small amount of amorphous carbon over the CNFs [37,43]. The wide and weak peak between 1000 and $1200 \mathrm{~cm}^{-1}$ may be due to the presence of some groups such as $\mathrm{C}=\mathrm{O}$ and C-O [37,44]. Therefore, from Raman spectrum of CNFs/PTFE electrodes can be deduced that CNFs used has a low degree of structural disorder, a low degree of oxidation and a small amount of amorphous carbon, being mainly crystalline graphitic carbons.

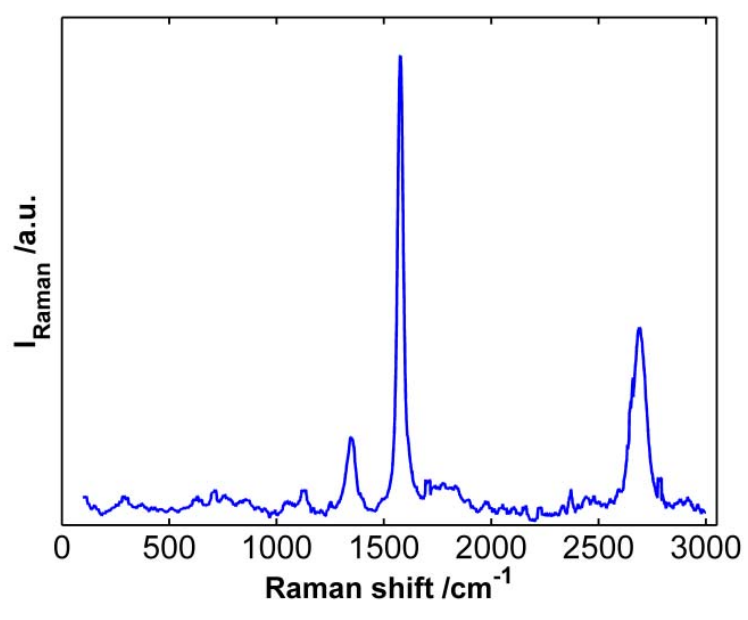

Fig. 4: Confocal Raman spectrum of CNFs/PTFE electrode.

\subsection{Electrochemical behaviour of CNFs/PTFE electrodes.}

Two different reversible redox systems were selected to probe the electrochemical performance of the electrodes fabricated with CNFs directly on the PTFE filter. Ferrocenemethanol and $\mathrm{Ru}(\mathrm{bipy})_{3}{ }^{2}$ are usually used as reference systems in electrochemistry to prove the good performance of new electrodes and devices,

Ferrocenemethanol is a chemical system that undergoes a one-electron, outer-sphere redox reaction showing a good chemical stability in an aerobic aqueous environment. 
The cyclic voltammograms (CVs) of the proposed $\mathrm{CNFs} / \mathrm{PTFE}$ electrode in $8.6 \cdot 10^{-4} \mathrm{M} \mathrm{FcMeOH}$ and 0.1 $\mathrm{M} \mathrm{KCl}$ aqueous solution at different scan rates, from 0.01 to $0.20 \mathrm{~V} \cdot \mathrm{s}^{-1}$, were investigated. From $\mathrm{CVs}$ shown in Figure 5 a practically reversible behaviour is observed, with anodic peaks around $+0.30 \mathrm{~V}$ and the corresponding cathodic peaks around $+0.17 \mathrm{~V}$, both related to oxidation and subsequent reduction of $\mathrm{FcMeOH} / \mathrm{FcMeOH}^{+}$. A slight shift of the peak potentials in CVs of Figure 5 respect to a the expected values for a revesible couple is appreciated. This behaviour can be related to the resistance of the thin $\mathrm{CNF}$ film. The formal potential of $\mathrm{FcMeOH} / \mathrm{FcMeOH}^{+}$ system is around $+0.238 \pm 0.006 \mathrm{~V}$. It can be also appreciated that peak currents are clearly dependent on the scan rate.

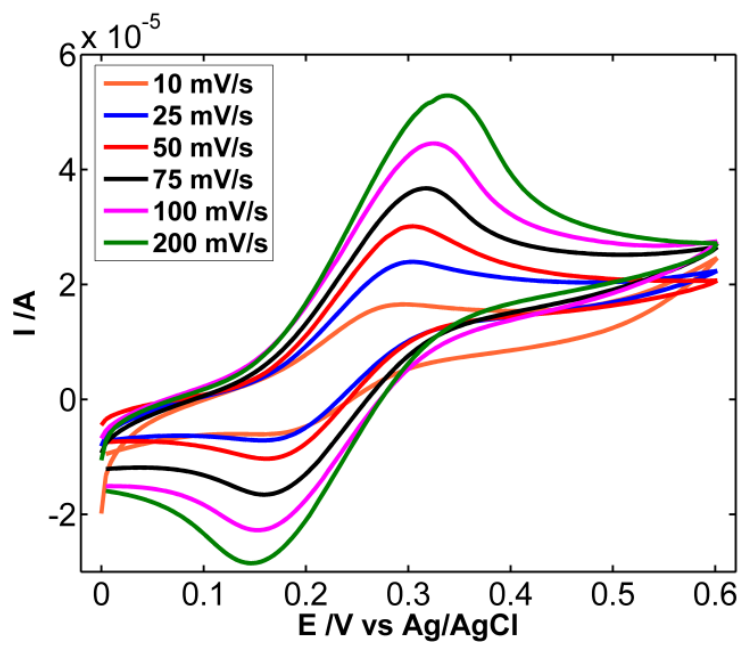

Fig. 5: Cyclic voltammograms of $8.6 \cdot 10^{-4} \mathrm{M}$ FcMeOH and 0.1 $\mathrm{M} \mathrm{KCl}$ aqueous solutions, recorded at different scan rates, from 0.01 to $0.20 \mathrm{~V} \cdot \mathrm{s}^{-1}$, between $0.00 \mathrm{~V}$ and $+0.60 \mathrm{~V}$. $\mathrm{V}_{\text {added }}=150$ $\mu \mathrm{L}$.

It was found that there are linear relationships with good correlation coefficients between the peak current, both in the anodic $\left(\mathrm{I}_{\mathrm{p}}^{\text {an }}\right)$ and in the cathodic $\left(\mathrm{I}_{\mathrm{p}}{ }^{\text {cat }}\right)$ sweeps, and the square root of the scan rate $\left(\mathrm{I}_{\mathrm{p}}{ }^{\text {an }}(\mathrm{A})=\right.$ $8.4 \cdot 10^{-5} \cdot \mathrm{v}^{1 / 2}\left(\mathrm{~V} \cdot \mathrm{s}^{-1}\right)^{1 / 2}+8.6 \cdot 10^{-7}, \mathrm{R}^{2}=0.999$, residual standard error $\left(\mathrm{S}_{\mathrm{yx}}\right)=4.5 \cdot 10^{-7} ; \mathrm{I}_{\mathrm{p}}^{\text {cat }}(\mathrm{A})=-5.4 \cdot 10^{-5} \cdot \mathrm{v}^{1 / 2}$ $\left.\left(\mathrm{V} \cdot \mathrm{s}^{-1}\right)^{1 / 2}-3.5 \cdot 10^{-7}, \mathrm{R}^{2}=0.994, \mathrm{~S}_{\mathrm{yx}}=6.0 \cdot 10^{-7}\right)$. These relationships indicate that the oxidation of $\mathrm{FcMeOH}$ is a diffusive controlled electrochemical process that follows the Randles-Sevcik equation [45, 46]. The good linear relationships demonstrate the good performance of the electrodes even in presence of a small ohmic drop due to the resistance of the film. It can be found in the literature values of the diffusion coefficient of $\mathrm{FcMeOH}$ that changes between $7 \cdot 10^{-6}$ and $7.8 \cdot 10^{-6} \mathrm{~cm}^{2} / \mathrm{s}$ [47-50]. For this work a mean value of $7.5 \cdot 10^{-6} \mathrm{~cm}^{2} / \mathrm{s}$ was assumed. Therefore, taking $\mathrm{C}=8.6 \cdot 10^{-4} \mathrm{M}$ as the $\mathrm{FcMeOH}$ concentration and $\mathrm{n}=1$ as the number of electrons involved in the redox reaction, the effective area of this $\mathrm{CNFs} / \mathrm{PTFE}$ electrode is calculated from regression values of $\mathrm{I}_{\mathrm{p}}{ }^{\text {an }} v s$ $\mathrm{v}^{1 / 2}$ obtaining a value of $0.13 \mathrm{~cm}^{2}$.

The second system used to test the electrochemical performance of the new electrodes, $\mathrm{Ru}(\text { bipy })_{3}{ }^{2+}$, also undergoes a one-electron, outer-sphere redox reaction. The CVs of the CNFs/PTFE electrode in $1 \cdot 10^{-3} \mathrm{M}$ $\mathrm{Ru}$ (bipy) ${ }_{3}{ }^{2+}$ and $1 \mathrm{M} \mathrm{KNO}_{3}$ aqueous solution at different scan rates in the range of $0.01-0.20 \mathrm{~V} \cdot \mathrm{s}^{-1}$ were studied (Figure 6).

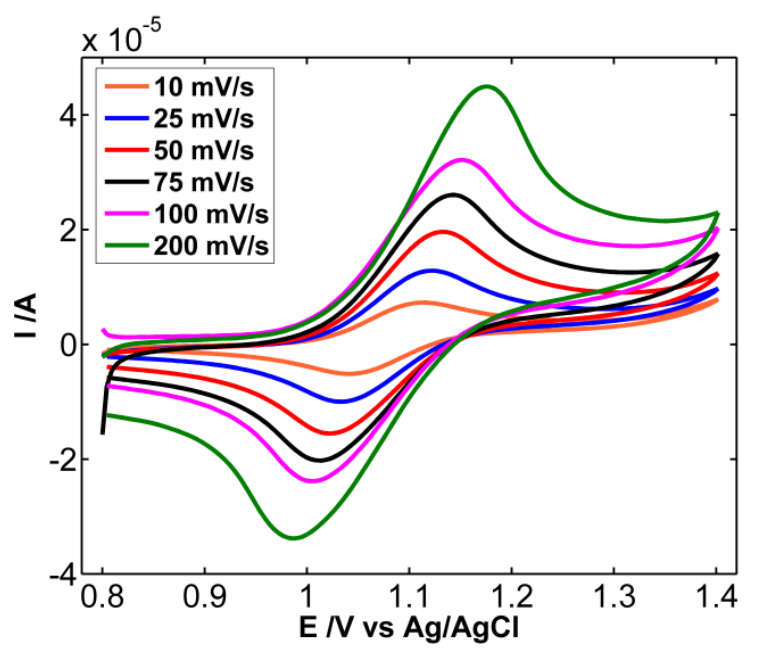

Fig. 6: Cyclic voltammograms of $1.7 \cdot 10^{-3} \mathrm{M} \mathrm{Ru}(\text { bipy })_{3}{ }^{2+}$ and $0.2 \mathrm{M} \mathrm{KNO}_{3}$ aqueous solutions, recorded at different scan rates, form 0.01 to $0.20 \mathrm{~V} \cdot \mathrm{s}^{-1}$, between $+0.80 \mathrm{~V}$ and $+1.40 \mathrm{~V}$. $\mathrm{V}_{\text {added }}=$ $150 \mu \mathrm{L}$.

Here, it is also appreciated a reversible behaviour, with anodic peaks around $+1.15 \mathrm{~V}$ and the corresponding cathodic peaks around $+1.00 \mathrm{~V}$ related to oxidation and following reduction of $\mathrm{Ru}$ (bipy) ${ }_{3}{ }^{2+} / \mathrm{Ru}$ (bipy) $)_{3}{ }^{3+}$. The formal potential of $\mathrm{Ru}$ (bipy) ${ }_{3}{ }^{2+} / \mathrm{Ru}$ (bipy) ${ }_{3}{ }^{3+}$ system is around $+1.077 \pm$ $0.003 \mathrm{~V}$. Now, it was also obtained linear relationships with good correlation coefficients between the anodic $\left(\mathrm{I}_{\mathrm{p}}{ }^{\mathrm{an}}\right)$ and cathodic peak currents $\left(\mathrm{I}_{\mathrm{p}}{ }^{\text {cat }}\right)$ and the square root of the scan rate $\left(\mathrm{I}_{\mathrm{p}}{ }^{\text {an }}(\mathrm{A})=7.9 \cdot 10^{-5} \cdot \mathrm{v}^{1 / 2}\left(\mathrm{~V} \cdot \mathrm{s}^{-1}\right)^{1 / 2}-\right.$ $2.3 \cdot 10^{-7}, \mathrm{R}^{2}=0.999, \mathrm{~S}_{\mathrm{yx}}=2.7 \cdot 10^{-7} ; \mathrm{I}_{\mathrm{p}}^{\text {cat }}(\mathrm{A})=-6.7 \cdot 10^{-}$ $\left.{ }^{5} \cdot \mathrm{v}^{1 / 2}\left(\mathrm{~V} \cdot \mathrm{s}^{-1}\right)^{1 / 2}+1.2 \cdot 10^{-7}, \mathrm{R}^{2}=0.995, \mathrm{~S}_{\mathrm{yx}}=6.1 \cdot 10^{-7}\right)$. From these relationships a diffusive controlled electrochemical process that follows the RandlesSevcik equation can be deduce for $\mathrm{Ru}(\text { bipy })_{3}{ }^{2+}$ oxidation $[42,43]$ Assuming as effective area the value calculated from the $\mathrm{FcMeOH} \mathrm{CVs}, 0.13 \mathrm{~cm}^{2}, \mathrm{n}=1$ and $\mathrm{C}=1 \cdot 10^{-3} \mathrm{M}$, the diffusion coefficient of $\mathrm{Ru}(\text { bipy })_{3}{ }^{2+}$ was estimated from linear relationships of $\mathrm{I}_{\mathrm{p}}^{\text {an }}$ vs $\mathrm{v}^{1 / 2}$, 
obtaining a value of $3.3 \cdot 10^{-6} \mathrm{~cm}^{2} / \mathrm{s}$, in agreement with values found in bibliography [51].

The agreement between the results presented here for these two redox systems and obtained using the CNFs/PTFE electrode, and the values obtained from literature, demonstrates the good performance of these electrodes and its suitability in electrochemistry experiments.

\subsection{Electrochemical determination of vitamin $B_{12}$.}

As a proof of concept and with the main objective of showing the possibility of using these CNFs/PTFE electrodes in electroanalysis, the determination of vitamin $B_{12}$ was proposed. Square wave voltammetry (SWV) was selected as electrochemical technique in order to test the analytical performance of the electrodes. The oxidation of vitamin $\mathrm{B}_{12}$ in aqueous buffer solutions of $\mathrm{H}_{2} \mathrm{PO}_{4}{ }^{-} / \mathrm{HPO}_{4}{ }^{2-}(\mathrm{pH}=5)$ was studied.

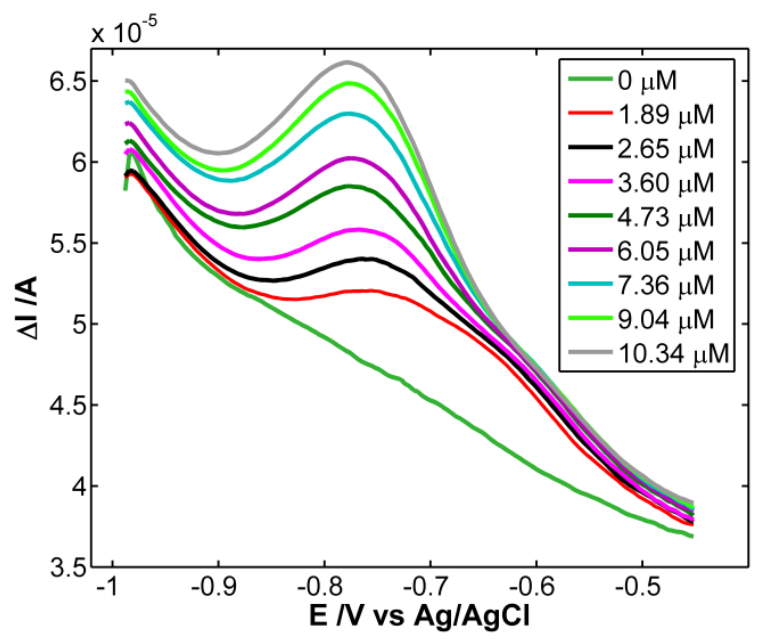

Fig. 7: Square wave voltammograms recorded with vitamin $B_{12}$ aqueous solutions in PBS medium $(\mathrm{pH}=5)$. Vitamin $\mathrm{B}_{12}$ concentrations were changed between $4.2 \cdot 10^{-7}$ and $1.0 \cdot 10^{-5} \mathrm{M}$.

Potential was scanned from $-1.00 \mathrm{~V}$ to $-0.45 \mathrm{~V}$ with a frequency of $15 \mathrm{~Hz}$ and a pulse amplitude of $0.050 \mathrm{~V}$. A set of vitamin $B_{12}$ standard solutions with different concentrations were prepared in the range of $4.2 \cdot 10^{-7}$ and $1.0 \cdot 10^{-5} \mathrm{M}$. Figure 7 shows the SWVs registered for different vitamin $\mathrm{B}_{12}$ concentrations including the signal of the buffer solution in absence of vitamin $\mathrm{B}_{12}$. Oxidation peak evolves around $-0.78 \mathrm{~V}$ assigned to
$\mathrm{Co}(\mathrm{I}) / \mathrm{Co}$ (II) oxidation process [52,53]. It is clearly observed a correlation between peak current and vitamin $\mathrm{B}_{12}$ concentration, that after robust regression to remove outliers values, a linear relationship was achieved: $\Delta \mathrm{I}(\mathrm{A})=0.97 \cdot \mathrm{C}_{\mathrm{B} 12}(\mathrm{M})+3.06 \cdot 10^{-6}$. The good determination coefficient, $\mathrm{R}^{2}=0.998$ and the low residual standard error, $\mathrm{S}_{\mathrm{yx}}=1.53 \cdot 10^{-7}$, indicates the good correlation between the peak current and the vitamin concentration. The linear range was between $9 \cdot 10^{-6}$ and $1.0 \cdot 10^{-6} \mathrm{M}$, being the detection limit of $4.5 \cdot 10^{-7} \mathrm{M}$. On the other hand, a test sample $4.7 \cdot 10^{-6} \mathrm{M}$ of vitamin $B_{12}$ was also prepared in the same buffer medium $(\mathrm{pH}=5)$ to evaluate the prediction capability of the calibration curve obtained.

The confidence interval of the concentration estimated was of $(4.87 \pm 0.41) \cdot 10^{-6} \mathrm{M}$ with a residual standard deviation (RSD) of $3.4 \%$.

CNFs/PTFE electrodes are a very interesting alternative to glassy carbon electrodes because of different reasons. For example, in a number of electrochemical reactions of organic compounds the reactants and/or the oxidation products are strongly adsorbed on the electrode surface. Particularly, it is well-known that the oxidation products of vitamin $\mathrm{B}_{12}$ are strongly adsorbed on glassy carbon electrodes [5255]. Different experiments have been carried out to compare the electrochemical responses of CNFs/PTFE and glassy carbon electrodes during the oxidation of vitamin $\mathrm{B}_{12}$. In both cases, the modification of the electrode surface occurs and physical or chemical cleaning procedures should be carried out to recover a clean surface before the next analysis. Electrochemical polishing was selected because of the simplicity of the method. As an example, SWVs were performed using GCE and CNFs/PTFE electrodes in a $9.73 \cdot 10^{-6} \mathrm{M}$ vitamin $\mathrm{B}_{12}$ solution in $\mathrm{PBS}$ buffer. After the experiments, the electrodes were electrochemically polished in PBS buffer by scanning the potential between -1.00 and $-0.20 \mathrm{~V}$ at $15 \mathrm{~Hz}$. After 9 consecutive SWVs the CNFs/PTFE electrode was completely recovered (current peak has decreased more than $95 \%$ from the analyte response). In the case of the GCE, the response after 9 cycles only decreased a $55 \%$, and even after $90 \mathrm{SWVs}$ in a row, current peak only decreased an $80 \%$. GCE only can be cleaned by physical methods because of the strong adsorption of the oxidation products. Thus, for example, if the electrode is going to be used in a flow injection analysis (FIA) system, obviously, the CNFs/PTFE electrode is much more suitable than the GCE.

Finally, and as a proof of concept of the usefulness of these CNFs/PTFE electrodes in analysis, synthetic 
samples of vitamin $\mathrm{B}_{12}$ were prepared, containing strong interfering compounds that usually are found in real samples. Thus, a set of complex samples of vitamin $\mathrm{B}_{12}$ containing two possible interfering compounds, such as vitamin $\mathrm{B}_{1}$ and vitamin $\mathrm{B}_{6}$, was prepared in a buffer solution of $\mathrm{H}_{2} \mathrm{PO}_{4}{ }^{-} / \mathrm{HPO}_{4}{ }^{2-}(\mathrm{pH}=$ 5). Different standard solutions with a fix concentration of vitamin $\mathrm{B}_{1}\left(3.2 \cdot 10^{-3}\right)$ and vitamin $\mathrm{B}_{6}$ $\left(5.3 \cdot 10^{-3}\right) \mathrm{M}$, and different concentrations of vitamin $\mathrm{B}_{12}$ in the range of $6 \cdot 10^{-6} \mathrm{M}$ and $1.2 \cdot 10^{-5} \mathrm{M}$ were prepared to evaluate the possibility of quantifying vitamin $\mathrm{B}_{12}$ in this very complex media. SWVs between $-1.00 \mathrm{~V}$ to $-0.20 \mathrm{~V}$ with a frequency of $15 \mathrm{~Hz}$ and a pulse amplitude of $0.050 \mathrm{~V}$ were registered.

The response of the background (black line in Figure 8.a), obtained from an aqueous solution of vitamin $B_{1}$ and vitamin $\mathrm{B}_{6}$ in buffer medium at $\mathrm{pH}=5$, shows a high oxidation current from $-1.00 \mathrm{~V}$ and $-0.50 \mathrm{~V}$. This background current affects significantly to the vitamin $\mathrm{B}_{12}$ determination, indicating that vitamins $\mathrm{B}_{1}$ and $\mathrm{B}_{6}$ are highly interfering at these vitamin $B_{12}$ concentrations, as can be deduced from SWVs shown in Figure 8.a. For this reason and trying to develop a suitable protocol to quantify vitamin $B_{12}$ in this complex medium a multivariate analysis of the data was performed. Therefore, taking into account not only the current peak but also the current values in the whole SWV registered between $-1.00 \mathrm{~V}$ and $-0.20 \mathrm{~V}$ for each concentration of vitamin $\mathrm{B}_{12}$, multivariate regression was carried out using partial least squares regression (PLSR) [56].

In this data analysis, each concentration was replicated three times, working with 27 dependent variables, being 200 the number of predictor potentials that corresponds with the number of potentials measured in each SWV.

Figure 8.b and 8.c show the deconvolution of the vitamin mixtures, where loadings vs potential and scores vs vitamin B12 concentration for the two latent values were plotted, respectively.

The first latent variable (blue line in Figure 8.b and 8.c) is related to vitamin $B_{12}$ because it shows a linear relationship with the changes of vitamin $B_{12}$ concentration (Figure 8.c).

The loadings of this first latent variable (Figure 8.b) can be related to vitamin $\mathrm{B}_{12}$ voltammogram with a peak current at $-0.78 \mathrm{~V}$, similar value to that obtained in pure vitamin $B_{12}$ solutions (Figure 7). The second latent variable (pink line in Figure 8.b and 8.c) is related to the background current because no correlation with vitamin $\mathrm{B}_{12}$ is appreciated (Figure 8.c). The regression model constructed only with the first latent variable provides neither good enough regression parameters nor correct predictions because of the significant contribution of the background medium. Thus, also the second latent variable has to be taken into account for a good quantification of vitamin $\mathrm{B}_{12}$ in this highly interfering medium. Therefore, regression model was constructed with two latent variables related to the main components that contribute to the electrochemical signal.
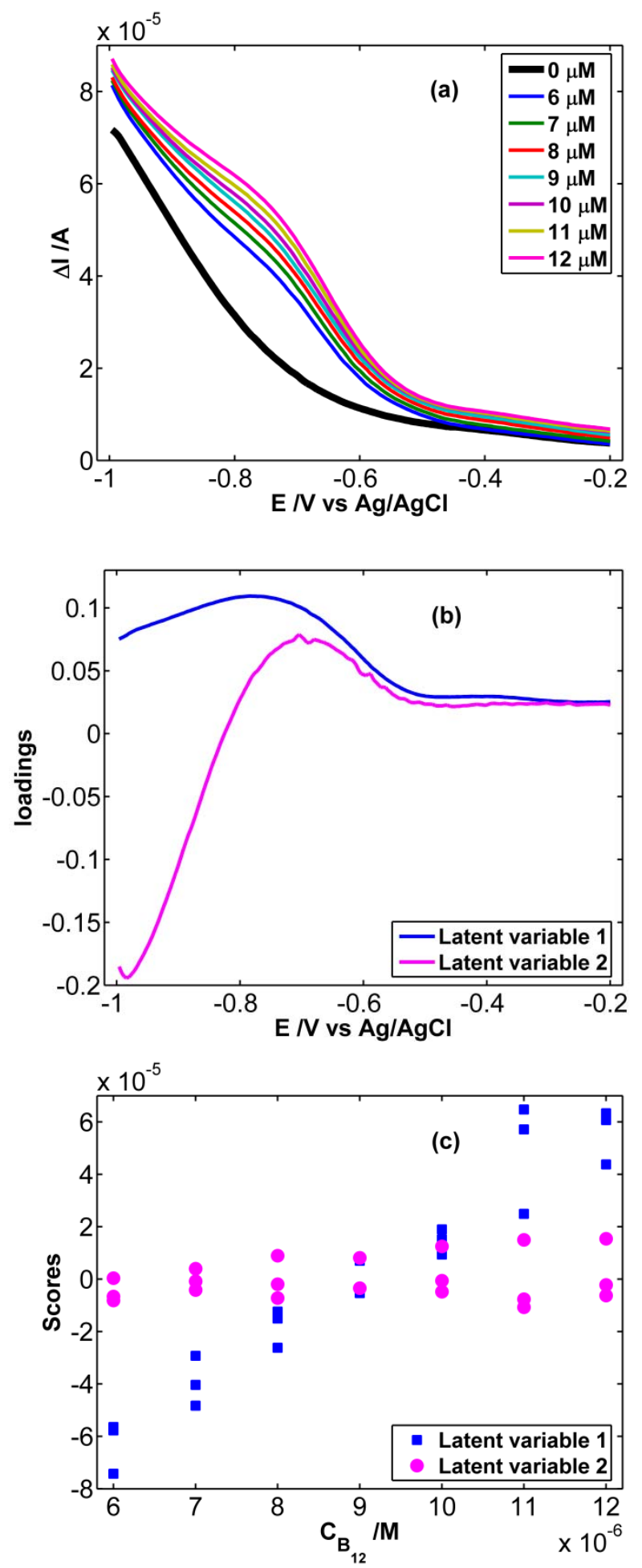
Fig. 8: (a) Square wave voltammograms recorded with vitamin $\mathrm{B}_{12}$ aqueous solutions in PBS medium $(\mathrm{pH}=5)$ with vitamin $\mathrm{B}_{1}$ $3.2 \cdot 10^{-3}$ and vitamin $\mathrm{B}_{6} 5.3 \cdot 10^{-3} \mathrm{M}$. Deconvolution of the current data matrix after multivariate analysis: (b) loadings $v s$ potential and (c) scores vs vitamin $\mathrm{B}_{12}$ concentration for the two first latent variables.

The concentration of a vitamin $\mathrm{B}_{12}$ problem sample with a concentration of $9 \cdot 10^{-6} \mathrm{M}$ has been estimated with the following confidence interval: $[8.76 \pm$ $0.64] \cdot 10^{-6} \mathrm{M}, \mathrm{RSD}=2.8 \%$.

Consequently, analysing all the results obtained with the different systems presented above, we have demonstrated the good performance of the $\mathrm{CNFs} / \mathrm{PTFE}$ electrodes fabricated and presented in this work, both in simple and complex media, indicating their usefulness for electroanalytical applications and proving that the resistance of the CNFs film does not have influence in the quantitative responses.

\section{Conclusions}

CNFs/PTFE electrodes were fabricated by filtering known amounts of CNFs solutions through PTFE filters. These CNFs modified filters, with the corresponding electrical contacts, were directly used as electrodes. The good electrochemical performance of the CNFs/PTFE electrodes was demonstrated by estimating the effective area of the electrodes with ferrocenemethanol and calculating the diffusion coefficient of $\mathrm{Ru}$ (bipy) ${ }_{3}{ }^{2+}$.

The electroanalytical quantification of vitamin $B_{12}$ in a buffered aqueous medium (PBS, $\mathrm{pH}=5$ ) was performed, getting very good linear correlations between the current peak of the square wave voltammograms and the vitamin $\mathrm{B}_{12}$ concentration. The good prediction of the model indicates that this vitamin can be properly estimated with the CNFs/PTFE electrodes. Finally, the quantification of vitamin $\mathrm{B}_{12}$ was carried out in a highly interfering medium, such as mixtures in PBS medium with vitamin $B_{1}$ and vitamin $B_{6}$ in concentrations 500 times higher than vitamin $B_{12}$. In this complex system multivariate analysis of the square wave voltammograms was essential, using the whole set of intensity current data registered from $-1.00 \mathrm{~V}$ to -0.20 $\mathrm{V}$. Two latent variables were required to properly explain the correlation between current and vitamin $\mathrm{B}_{12}$ concentrations because the background medium of $\mathrm{PBS}$, vitamin $\mathrm{B}_{1}$ and vitamin $\mathrm{B}_{6}$, has a great influence in the square wave voltammograms. Partial Least Squares Regression supplies very good correlation between the scores of the two first latent variables and vitamin $\mathrm{B}_{12}$ concentration, getting an excellent estimation of vitamin $B_{12}$ in a problem sample.

\section{Acknowledgements}

We greatly thank Dra. Virginia Ruiz from CIDETEC (Spain) for supplying carbon nanofibres. The financial support by the Junta de Castilla y León (GR71, BU349-U13) and the Ministerio de Economía y Competitividad (CTQ2014-55583-R, CTQ201461914-EXP) is gratefully acknowledged. D.I. thanks Ministerio de Economía y Competitividad for his predoctoral FPI fellowship.

\section{References}

[1] J. Huang, Y. Liu, T. You, Anal. Methods. 2010, 2, 202211.

[2] Y.A. Kim, T. Hayashi, M. Endo, M.S. Dresselhaus, Carbon Nanofibers, in: Handbook of Nanomatererials, Springer, 2013: pp. 233-262.

[3] G.G. Tibbetts, J. Cryst. Growth. 1984, 66, 632-638.

[4] S.-U. Kim, K.-H. Lee, Chem. Phys. Lett. 2004, 400, $253-$ 257.

[5] P. Serp, M. Corrias, P. Kalck, Appl. Catal. A. 2003, 253, $337-358$.

[6] M.L. Toebes, F.F. Prinsloo, J.H. Bitter, A.J. Van Dillen, K.P. De Jong, J. Catal. 2003, 214, 78-87.

[7] E.S. Steigerwalt, G.A. Deluga, C.M. Lukehart, J. Phys. Chem. B. 2002, 106, 760-766.

[8] A.D. Lueking, R.T. Yang, N.M. Rodriguez, R.T.K. Baker, Langmuir. 2004, 20, 714-721.

[9] D.J. Browning, M.L. Gerrard, J.B. Lakeman, I.M. Mellor, R.J. Mortimer, M.C. Turpin, Nano Lett. 2002, 2, 201-205.

[10] A.J. Rodriguez, M.E. Guzman, C.S. Lim, B. Minaie, Carbon 2011, 49, 937-948.

[11] A. Peyvandi, P. Soroushian, N. Abdol, A.M. Balachandra, Carbon 2013, 49, 175-186.

[12] A. Merkoçi, M. Pumera, X. Llopis, B. Pérez, M. del Valle, S. Alegret, TrAC Trends Anal. Chem. 2005, 24, 826-838.

[13] L. Agüí, P. Yáñez-Sedeño, J.M. Pingarrón, Anal. Chim. Acta. 2008, 622, 11- 47.

[14] R. Thangaraj, S. Nellaiappan, R. Sudhakaran, A.S. Kumar, Electrochim. Acta. 2014, 123, 485-493. 
[15] A. Arvinte, F. Valentini, A. Radoi, F. Arduini, E. Tamburri, L. Rotariu, G. Palleschi, C. Bala, Electroanalysis. 2007, 19, 1455-1459.

[16] L. Wu, X. Zhang, H. Ju, Anal. Chem. 79 (2007), 79, 453458.

[17] J. Huang, Y. Liu, H. Hou, T. You, fibers modified electrode, Biosens. Bioelectron. 2008, 24, 632-637.

[18] Q. Guo, J. Huang, P. Chen, Y. Liu, H. Hou, T. You, Sensors Actuators, B. 2012, 163,179-185.

[19] J. Huang, D. Wang, H. Hou, T. You, Adv. Funct. Mater. 2008, 18, 441-448.

[20] Y. Liu, J. Huang, H. Hou, T. You, Electrochem. Commun. 2008, 10, 1431-1434.

[21] R.H. Baughman, C. Cui, A.A. Zakhidov, Z. Iqbal, J.N. Barisci, G.M. Spinks, G.G. Wallace, A. Mazzoldi, D. De Rossi, A.G. Rinzler, O. Jaschinski, S. Roth, M. Kertesz, Sience 1999 284, 1340-1344.

[22] Hussein, L., Urban, G., and Krüger, M. Phys. Chem. Chem. Phys. 2011, 13, 5831-5839.

[23] A.G. Rinzler, J. Liu, H. Dai, P. Nikolaev, C.B. Huffman, F.J. Rodriguez-Macías, P.J. Boul, A.H. Lu, D. Heymann, D.T. Colbert, R.S. Lee, J.E. Fischer, A.M. Rao, P.C. Eklund, R.E. Smalley, Appl. Phys. A 1998, 67, 29-37

[24] J.J. Gooding, Electrochim. Acta. 2005, 50, 3049-3060.

[25] J. Wang, Y. Lin, TrAC Trends Anal. Chem. 2008, 27, 619-66.

[26] L. Matlock-Colangelo, A.J. Baeumner, Lab Chip. 2012, 12, 2612-2620.

[27] F. Marken, M.L. Gerrard, I.M. Mellor, R.J. Mortimer, C.E. Madden, S. Fletcher, K. Holt, J.S. Foord, R.H. Dahm, F. Page, Electrochem. Commun. 2001, 3, 177-180.

[28] V. Vamvakaki, K. Tsagaraki, N. Chaniotakis, Anal. Chem. 2006, 78, 5538-5542.

[29] J.E. Koehne, M. Marsh, A. Boakye, B. Douglas, I.Y. Kim, S.-Y. Chang,D.P. Jang, K.E. Bennet, C. Kimble, R. Andrews, M. Meyyappan, K.H. Lee, Analyst. 2011, 136, 1802-1805.

[30] J. Zhang, J. Lei, Y. Liu, J. Zhao, H. Ju, Biosens. Bioelectron. 2009, 24, 1858-1863.

[31] X. Tang, Y. Liu, H. Hou, T. You, Talanta. 2011, 831410 1414.

[32] Z. Li, X. Cui, J. Zheng, Q. Wang, Y. Lin, Anal. Chim. Acta. 2007, 597, 238-244.

[33] S.S. Kumar, R.S. Chouhan, M.S. Thakur, Anal. Biochem. 2010, 398, 139-149.

[34] G.L. Kreft, O.C. De Braga, A. Spinelli, Electrochim. Acta. 2012, 83, 125-132.

[35] D. Lexa, J.-M. Savéant, Acc. Chem. Res. 1982, 140, $297-$ 309.
[36] J. Garoz-Ruiz, S. Palmero, D. Ibañez, A. Heras, A. Colina, Electrochem. Commun. 2012, 25, 1-4.

[37] P. Li, T.J. Zhao, J.H. Zhou, Z.J. Sui, Y.C. Dai, W.K. Yuan, Carbon 2005, 43, 2701-2710.

[38] K. Tamargo-Martínez, S. Villar-Rodil, A. MartínezAlonso, J.M.D. Tascón, Mater. Chem. Phys. 2013, 138, 615-622.

[39] A. Cuesta, P. Dhamelincourt, J. Laureyns, A. MartinesAlonso, J.M.D. Tascon, Carbon 1994, 32, 1523-1532.

[40] F. Tuinstra, L. Koenig, J. Chem. Phys. 1970, 53, 11261130.

[41] S. Maldonado, K.J. Stevenson, J. Phys. Chem. B. 2005, 109, 4707-4716.

[42] A. Cuesta, P. Dhamelincourt, J. Laureyns, A. MartínezAlonso, J.M.D. Tascón, J. Mater. Chem. 1998, 8, 28752879.

[43] T. Jawhari, A. Roid, J. Casado, Carbon 1995, 33, 15611565.

[44] N. Keller, N.I. Maksimova, V.V. Roddatis, M. Schur, G. Mestl, Y.V. Butenko, V.L. Kuznetsov, R. Schlogl, Angew. Chemie - Int. Ed. 2002, 41, 1885-1888.

[45] J. Wang, Analytical Electrochemistry, 3rd ed., New York, 206.

[46] A.J. Bard, L.R. Faulkner, eds., Electrochemical methods. Fundamentals and applications., 2nd ed., John Wiley \& sons, New York, 2001.

[47] W. Li, C. Tan, M.A. Lowe, H.D. Abruña, D.C. Ralph, ACS Nano. 2011, 5, 2264-2270.

[48] P. Sun, M.V. Mirkin, Anal. Chem. 2006, 78, 6526-6534.

[49] J. Velmurugan, P. Sun, M. V Mirkin, J. Phys. Chem. C. 2009, 113, 459-464.

[50] C. Amatore, N. Da Mota, C. Lemmer, C. Pebay, C. Sella, L. Thouin, Anal. Chem. 80 (2008) 9483-9490.

[51] J.V Macpherson, C.J. Slevin, P.R. Unwin, J. Chem. Soc. Faraday Trans. 1996, 92, 3799-3805.

[52] S.R. Hernández, G.G. Ribero, H.C. Goicoechea, Talanta. 2003, 61, 743-753.

[53] D. Zheng, T. Lu, J. Electroanal. Chem. 1997, 429, 61-65.

[54] N. Yang, Q. Wan, X. Wang, Electrochim. Acta. 2005, 50, 2175-2180.

[55] J.H. Zagal, M.J. Aguirre, M.A. Páez, J. Electroanal. Chem. 1997, 437, 45-52.

[56] B.-H. Mevik, R. Wehrens, J. Stat. Softw. 2007, 18, 1-24. 